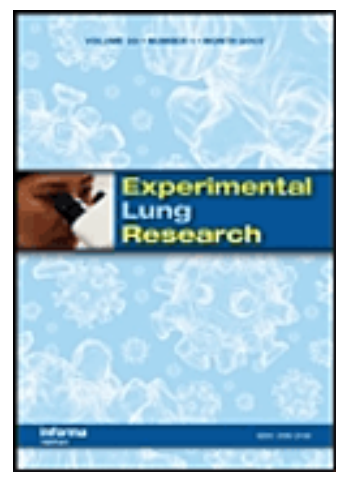

\title{
Isolating and Culturing of Sputum Macrophages: A Potential Ex Vivo/In Vitro Model
}

\begin{tabular}{|r|l|}
\hline Journal: & Experimental Lung Research \\
\hline Manuscript ID & UELR-2018-0098.R2 \\
\hline Manuscript Type: & Original Paper \\
\hline Dute Submitted by the & n/a \\
\hline Complete List of Authors: & $\begin{array}{l}\text { Bølling, Anette Kocbach ; Norwegian Institute of Public Health,, Domain } \\
\text { of Infection Control and Environmental Health } \\
\text { Steensen, Tonje Berg; Norwegian Institute of Public Health,, Domain of } \\
\text { Infection Control and Environmental Health } \\
\text { Alexis, N.E.; University of North Carolina, Chapel Hill, Center for } \\
\text { Environmental Medicine, Asthma and Lung Biology } \\
\text { Sikkeland, Liv Ingunn Bjoner; University of Oslo, Institute of Clinical } \\
\text { Medicine; Oslo University Hospital, Rikshospitalet, Dept. of Respiratory } \\
\text { Medicine }\end{array}$ \\
\hline Keywords: & induced sputum, airway macrophages, cell culture \\
\hline &
\end{tabular}

\section{SCHOLARONE Manuscripts}




\title{
Isolating and Culturing of Sputum Macrophages: A Potential Ex Vivo/In Vitro Model
}

\author{
${ }^{1}$ Anette Kocbach Bølling, ${ }^{1}$ Tonje Berg Steensen, ${ }^{2}$ Neil E. Alexis, ${ }^{3}$ Liv Ingunn Bjoner Sikkeland \\ ${ }^{1}$ Domain of Infection Control and Environmental Health, Norwegian Institute of Public Health, \\ Oslo, Norway. ${ }^{2}$ Center for Environmental Medicine, Asthma and Lung Biology, UNC Chapel \\ Hill, Chapel Hill, North Carolina, USA. ${ }^{3}$ Department of Respiratory Medicine, Rikshospitalet, \\ Oslo University Hospital AND University of Oslo, Oslo, Norway
}

Correspondence to:

Liv Ingunn Bjoner Sikkeland, Department of Respiratory Medicine Institute of Clinical Medicine, Faculty of Medicine University of Oslo PostBox 4950 Nydalen, 0424 Oslo Norway

l.i.b.sikkeland@medisin.uio.no

Key words: Induced sputum, airway macrophages and cell culture. 


\section{Abstract}

Purpose

This paper aimed to test whether induced sputum samples acquired from human volunteers could be used to isolate and culture airway macrophages for in vitro exposures. This was assessed in terms of the culturing success rate, culture purity, viability and responsiveness of cultured cells.

\section{Materials and Methods}

The isolation and culturing procedure was performed over three days. On Day 1, induced sputum samples were obtained, processed and seeded in culture wells. Differential cell counts and viability tests were performed to allow for calculation of viable macrophage numbers and appropriate sample dilution. After a $1 \mathrm{~h}$ rest seeded wells were washed to remove non-adherent cells, resulting in macrophage isolation. Then, cells rested overnight (Day 1 - Day 2), before in vitro exposure for 2-24 h (Day 2 - Day 3). The criteria for progressing into the culturing procedure was cell viability $>40 \%$ and total cell number $>10^{6}$. Successful culturing was evaluated based on cell attachment $(\mathrm{N}=40)$. Culture purity by differential cell analysis and viability was monitored during culturing $(\mathrm{N}=4-8)$. Macrophage responsivity was assessed by measurement of inflammatory cytokine gene expression $(\mathrm{N}=4)$ and cytokine levels $(\mathrm{N}=6)$ following in vitro exposure to lipopolysaccharide (LPS) (2-24 h) and live bacteria (S. aureus) (4h).

\section{Results}

Overall, $88 \%(35 / 40)$ of the samples acquired were suitable for isolation, and $80 \%(32 / 40)$ were successfully progressed through the 2-3 day culturing protocol. Macrophage purity $(88 \%)$ and viability ( $85 \%$ ) were adequate. Moreover, cultured macrophages were responsive to in vitro 
stimulation with LPS and viable $S$. aureus showing positive mRNA responses for TNF $\alpha$, IL-1 $\beta$ and IL-8 and release of IL-1 $\beta$, respectively.

\section{Conclusion}

Sputum macrophage isolation by plate adherence and subsequent culturing of sputum macrophages was successfully performed and represents a promising in vitro model for e examination of airway macrophage behavior. 


\section{Introduction}

Culturing macrophages from the airways of humans provides an opportunity to examine their phenotypic and functional characteristics in isolation, in order to better understand their role in maintaining an immunologically healthy airway environment. Specifically, one can examine ex vivo, biological responses of macrophages both before and following exogenously applied environmental pollutants. Induced sputum is a relatively non-invasive method by which to acquire airway macrophages from the surfaces of the central airways, ${ }^{[1]}$ a region of the lung where pathophysiologic events often occur. The majority of induced sputum samples contain a sufficient number of viable cells that allow for ex vivo/in vitro assays to be performed.[2] In healthy volunteers, sputum samples comprise mainly macrophages and neutrophils, and to a lesser extent monocytes, eosinophils, lymphocytes and basophils. Therefore, in order to study macrophages in isolation, an optimal enrichment technique is needed to avoid the confounding effects from other cell types such as neutrophils. This is important both when measuring mRNA expression and protein levels. To date, a few isolation methods, including a cell culture method, have been attempted but none have proven optimally effective. Horva'th and co-authors (1998) isolated sputum macrophages for western blotting by culturing the whole sputum sample on plates but had varied success in terms of macrophage adherence and subsequent isolation. ${ }^{[3]}$ Others, including our group have utilized magnetic bead isolation, cell sorting by flow cytometry 
and a culture method, but concluded these methods either have significant limitations for use in subsequent in vitro assays, or require further refinement. ${ }^{[4,5]}$

The purpose of this paper is to describe a fully refined method to culture and isolate macrophages from induced sputum samples acquired from human volunteers. Method criteria under examination were macrophage viability, macrophage purity, success and survival rate of macrophages post-isolation, and post-culture macrophage activation following exogenously applied inflammatory stimuli, such as LPS and viable bacteria. We report results from 33 healthy subjects who underwent sputum induction for culturing of airway macrophages.

\section{Materials and Methods \\ Experimental Design}

As shown in Figure 1, the entire experimental protocol occurred over 3 days. On Day 1, sputum induction, sample processing, cell seeding and adherence of the cells took approximately 4 hours (h) to complete. An overnight rest period was followed by an LPS $(1 \mu \mathrm{g} / \mathrm{ml})$ exposure on Day 2. Cells were harvested for mRNA analysis after 2, 5, 8 or $24 \mathrm{~h}$ exposure (Day 2 or 3 ). The culture purity and macrophage viability was assessed in the exposure time interval $(0-24 \mathrm{~h})$.

\section{Subjects}

Healthy adult volunteers ( $\mathrm{N}=33$; ages 20 to 58 years old; 16 female vs. 17 male) underwent sputum induction. All volunteers were non-smokers and were free from upper respiratory tract infections for a period at least 4 weeks prior to study enrollment. Informed consent was obtained from all volunteers and ethical approval was obtained from the Norwegian Regional Committees for Medical and Health Research Ethics (REC; 2015/1322). Five of the volunteers provided 2 
samples, while one volunteer provided 3 samples. Thus, the total number of sputum inductions preformed was 40 .

\section{Sputum induction and processing}

Induced sputum collection was performed according to Alexis et al. ${ }^{[6]}$ In brief, postbronchodilator spirometry $\left(\mathrm{FEV}_{1}\right)$ was measured (Airomir Autohaler, Teva) and safety values (10 $\%$ and $20 \%$ fall from post bronchodilator $\mathrm{FEV}_{1}$ ) were determined. Then, hypertonic saline of 3 $\%(\mathrm{w} / \mathrm{V}), 4 \%$, and $5 \%$ was inhaled via an ultrasonic nebulizer (DeVilbiss, Sunrise Medicals) during three 7-minute inhalation periods. Sample expectorates were collected after each inhalation period into a sterile specimen cup placed on ice. Care was taken to avoid throat scraping to minimize potential squamous epithelial cell contamination. Whole sputum samples were dissolved in $0.1 \%(\mathrm{w} / \mathrm{V})$ dithiothreitol (DTT)(Sigma, MO, USA) in cold Phosphate Buffered Saline (PBS) on a shaker for 10 minutes before dilution to $0.05 \%$ DTT in PBS. The sample was filtered through a $50 \mu \mathrm{M}$ nylon mesh filter (Sintab, Sweden) and centrifuged at $340 \mathrm{x}$ $\mathrm{g}$ for 5 minutes. The cell pellet was resuspended in $1 \mathrm{ml}$ complete cell culture medium, consisting of RPMI 1640 (Sigma-Aldrich, St. Louis, MO) supplemented with $10 \%$ heat inactivated fetal bovine serum (Sigma-Aldrich), $100 \mathrm{U} / \mathrm{ml}$ penicillin (Sigma-Aldrich), $100 \mu \mathrm{g} / \mathrm{ml}$ streptomycin (Sigma-Aldrich), $2 \mathrm{mM}$ L-glutamine (Sigma-Aldrich) and $0.5 \mathrm{mg} / \mathrm{ml} \mathrm{Gibco}^{\mathrm{TM}}$ Amphotericin B (Thermo Fisher Scientific). The sputum sample was kept on ice during all stages of the processing, except for the shaking with DTT.

The total cell counts were evaluated using a Bürker hemocytometer, combined with Trypan blue $(0.4 \%)$ (Sigma Aldrich) staining to determine leukocyte viability. Non-viable cells contained Trypan blue stain in the interior of the cell. Cytospins for the differential cell counts were obtained by adding 10000 cells at a concentration of $10^{6}$ cells $/ \mathrm{ml}$ to the cytospin slide chamber. 
The slides were centrifuged for $5 \mathrm{~min}$ at $140 \mathrm{x}$ g, and then air dried for 10 minutes. Then the slides were stained using Diff-Quik (Medion Diagnostics, Duedingen, Switzerland) and mounting with Eukitt quick-hardening mounting medium (Sigma-Aldrich, St. Louis, USA). The staining and mounting process took about 15 minutes, allowing for rapid differential cell counts and subsequent calculation of macrophage concentrations based on these counts. The cell suspension was then diluted to a concentration of $4.0 \times 10^{5}$ macrophages $/ \mathrm{ml}$. The initial criteria for processing and culturing sputum macrophages were a) cell viability above $40 \%$, based on the viability threshold suggested by the ERS/ATS working group on induced sputum ${ }^{[7]}$, and b) a total cell count greater than $10^{6}$ cells, based on the necessary number of wells for an in vitro exposure experiment.

\section{Culturing of airway macrophages}

The suspension of sputum cells was seeded in 12 or 48 well plates to yield $3.2 \times 10^{5}$ macrophages/well $(800 \mu \mathrm{L})$ or $10^{5}$ macrophages/well $(250 \mu \mathrm{L})$, respectively (Falcon, Corning inc., NY, USA). The 12 well plates were used for mRNA analysis since the mRNA yield was too low when using 48 well plates. The 48 well plates were applied for monitoring of cells during culturing. The cells were incubated for $1 \mathrm{~h}$ in an atmosphere of $37^{\circ} \mathrm{C}$ and $5 \% \mathrm{CO}_{2}$ to allow macrophages to attach to the culture wells. Then, the wells were washed twice with PBS and detached cells were discarded (supernatant), before fresh medium was added. Figure 2 shows sputum cells (on a cytospin) before seeding (a) and following attachment in the culture dish (b). Preliminary data (not shown) indicated high levels of pro-inflammatory cytokines post macrophage seeding (i.e. at -20 h, Figure 1), so we instilled a rest period of $20 \mathrm{~h}$ before in vitro exposure/stimulation.

\section{Monitoring of cells during culturing}


At different time points during the culturing, cells were monitored in terms of cell numbers (counting squares), viability (Trypan blue exclusion) and differential cell count (staining with Diff Quik for preparation of cytospins). The number of attached cells were counted in a square drawn onto the bottom of the cell culture plate using an $x-y$ axis grid, and presented as the percentage of the initial cell count (-20 h time point). For viability tests, the attached cells were stained for 1 min with 1:1 diluted Trypan blue $(0.4 \%)$ in cell culture medium. This was then replaced with 1:50 diluted Trypan blue to allow for light microscopy assessment, before a minimum of 150 cells were counted (Trypan blue exclusion). In addition, cells in suspension were used to monitor the viability of cells detached during culturing (1:10 dilution of Trypan blue).

Differential cell counts of detached cells post-culturing, was performed at the $0 \mathrm{~h}$ time point (Figure 1), using Accutase to detach the cells. In brief, cells were washed with PBS, incubated at $37{ }^{\circ} \mathrm{C}$ with Accutase for 9 min, with physical manipulation (shaking/knocking of plate) every third minute. Then, the cells were transferred to an Eppendorf tube and an additional rinsing of the well was performed with PBS, before centrifugation. A cytospin was prepared of these detached cells, and stained for differential cell counts as described above.

\section{$R N A$ isolation and reverse transcription-polymerase chain reaction (RT-PCR)}

For mRNA analysis, sputum macrophages were exposed to $1 \mu \mathrm{g} / \mathrm{mL}$ of the toll-like receptor (TLR)-4 agonist lipopolysaccharide (LPS) from E. coli strain 026:B6 (Sigma-Aldrich) for 2-24 h. Total RNA was extracted from approximately 300,000 sputum macrophages using QIAGEN RNeasy Mini Kit (VWR International, Oslo, Norway) with the addition of RNase-free DNase according to the manufacturer's instructions. $100 \mathrm{ng}$ of total RNA was reverse transcribed using TaqMan RT reagents (Applied Biosystems, Foster City, CA) in a final volume of $50 \mu 1$. Negative 
controls were performed to ensure that PCR amplification cDNA was not a result of contaminating, genomic DNA. Reverse-transcribed cDNA was amplified by using a TNF $\alpha$ probe/primer mix (Hs00174128_m1, 4331182, Applied Biosystems), or 200 nM primers (Eurogentec) and $100 \mathrm{nM}$ probes (Probelibrary, Exqion, Denmark) for human IL-1 $\beta$, IL-6 or IL8, and 1X TaqMan Universal Master Mix (Applied Biosystems) in a total volume of $25 \mu 1$. Primers were designed using Exiqon ProbeLibrary Assay Design Center (http://www.universalprobelibrary.com), and were constructed as follows: IL-1 $\beta$; left primer AAAGCTTGGTGATGTCTGGTC, right primer GGACATGGAGAACACCACTTG to probe 39, IL-6; left primer GCCCAGCTATGAACTCCTTCT, right primer GAAGGCAGCAGGCAACAC to probe 45, and IL-8; left primer AGACAGCAGAGCACACAAGC, right primer ATGGTTCCTTCCGGTGGT to probe 72. Human PGK (phosphoglyceratekinase 1) (4310885E, Applied Biosystems) served as endogenous control. Real-time PCR was performed using the Applied Biosystems prism 7900 sequence detector following the manufacturer's instructions. Results were expressed as fold induction of mRNA, which was determined by normalizing cytokine threshold cycle values against PGK. These data were further normalized against samples from unstimulated cells at $0 \mathrm{~h}$.

\section{Stimulation with viable bacteria and cytokine analysis}

To further test the responsivity of the sputum macrophages after $40-44 \mathrm{~h}$ in culture, the cells were exposed to viable bacteria for $4 \mathrm{~h}$ at the $20 \mathrm{~h}$ time-point. Staphylococcus aureus (S. aureus) strains Newman was a kind gift from Tadashi Baba, Juntendo University School of Medicine, Tokyo, Japan. Viable $S$. aureus were added to the cell culture at multiplicity of infection (MOI) of 1 and 10, corresponding to ratios of $S$. aureus to sputum macrophages of 1:1 and 10:1, respectively. After $4 \mathrm{~h}$ exposure to $\mathrm{S}$. aureus, the supernatant was harvested and centrifuged for 
$10 \mathrm{~min}$ at $100 \mathrm{x} \mathrm{g}$ to remove cells and for $10 \mathrm{~min}$ at $5000 \mathrm{x} \mathrm{g}$ to remove bacteria, and stored at -80 ${ }^{\circ} \mathrm{C}$ until cytokine analysis. The levels of IL-1 $\beta$ were determined by an enzyme-linked immunosorbent assay (ELISA) kits for human IL-1 $\beta$ from R\&D Systems Inc. (MN, USA) according to the manufacturer's instructions.

\section{Statistical analysis}

Statistical comparisons were performed using 2-way ANOVA with Bonferroni post-tests to assess effects of LPS stimulation. Additionally, to compare the cytokine gene expression level at $20 \mathrm{~h}$ compared to $0 \mathrm{~h}$, a one sample t-test with hypothetical value 1 (i.e. $0 \mathrm{~h}$ control value) was used. All analyses were performed in GraphPad Prism Version 5.04. In these analyses $\mathrm{p}<0.05$ was considered statistically significant, and the data reflected 4 independent experiments from 4 different subjects.

\section{Results}

\section{Sputum sample characteristics pre-culturing $(N=35)$}

Based on the initial criteria (mean viability $>40 \%$, total cell number $>10^{6}$ ), 35 of 40 sputum samples from healthy donors were suitable for culturing. Overview of sample characteristics of sputum samples $(\mathrm{N}=35)$ are given in Table 1 and Figure 3 . The mean ( \pm standard deviation $(\mathrm{SD}))$ number of total viable leukocytes in these samples was $5.5( \pm 5.3)$ million. With a mean macrophage percentage of $68( \pm 16) \%$, ranging from $26-93 \%$, this resulted in 0.5 to 14.1 million macrophages for culturing. The mean neutrophil percentage was $31( \pm 17) \%$, while the percentages of eosinophils and leukocytes were negligible (Table 1). Note that of these 35 
samples, 7 originated from participants that were invited to provide a sample a second or third time as their samples exhibited high cell numbers.

In three of the 35 samples there was not sufficient adherence of the macrophages to the cell culture well during the initial $1 \mathrm{~h}$ rest. These samples displayed relatively low macrophage percentages $(<60 \%)$, combined with a sub-optimal viability $(<60 \%)$, resulting in poor conditions for cellular attachment in the cell culture wells. For the remaining 32 samples, the culturing was successful (Figure 3). Exclusion of the 7 repeated visits resulted in 25 out of 32 samples with successful culturing, and a success rate for culturing of sputum macrophages of 78 $\%$.

\section{Purity of culture and cell survival $(N=3-8)$}

During sputum processing, macrophages were the dominating cell type $(58 \pm 7 \%)$ followed by neutrophils (23 $\pm 10 \%)$ and squamous epithelial cells $(19 \pm 9 \%)$ (Figure 4a). After $20 \mathrm{~h}$ in culture, differential cell counts of detached viable cells showed increased macrophage purity, with mean macrophage percentages of $88( \pm 11) \%$, with squamous epithelial cells as the only other identified cell type $(12 \pm 11 \%$ ) (Figure $4 b)$. To evaluate whether the squamous cell percentages were reduced during the seeding and culturing procedure, the percentages of squamous cells relative to macrophages should be considered. During sputum processing these squamous cell percentages were $27( \pm 17) \%$, while they were reduced to $14( \pm 8) \%$ after $20 \mathrm{~h}$ in culture, resulting in an average reduction of $47( \pm 21) \%$. 
The number of attached cells decreased for increasing incubation (Figure 5a), with a meanpercentage of attached cells of $70( \pm 15) \%$ for the $20 \mathrm{~h}$ time point which corresponds to $0.7 \times 10^{5}$ cells per well in 48 well plates. However, the mean viability of the attached cells remained relatively constant, around $85 \%$, throughout the incubation period, and at the $20 \mathrm{~h}$ time point the viability of the attached cells was $88( \pm 8) \%(n=8)$ (Figure $5 b)$. The viability for the detached macrophages (supernatant) was $83( \pm 8) \%(n=4)$.

\section{LPS stimulation and gene expression analysis $(N=4)$}

Macrophage activation was assessed by cytokine gene expression. The TNF $\alpha$ gene expression was 50 fold higher at the $-20 \mathrm{~h}$ compared to the $0 \mathrm{~h}$ time point $(\mathrm{p}<0.05)$, whereas the expression levels of IL-1 $\beta$, IL-6 and IL-8 were relatively unchanged during the same period (Figure 6). Thus, a $20 \mathrm{~h}$ rest of the macrophages post-culture, but pre LPS stimulation resulted in a low basal TNF $\alpha$ expression at the time of LPS exposure $(0 \mathrm{~h})$. The cells responded to LPS stimulation with significantly increased gene expression levels of TNF $\alpha$ at 2 and $5 \mathrm{~h}, \mathrm{IL}-1 \beta$ at $8 \mathrm{~h}$ and IL-6 at 2, 5 and $8 \mathrm{~h}$. These data confirm that the cultured sputum macrophages are capable of responding to inflammatory stimuli during an acute period of time but not chronic ( $24 \mathrm{~h})$.

\section{Stimulation with viable bacteria and protein analysis $(N=6)$}

The cells responded to exposure to viable $S$. aureus at multiplicity of infection of 1 and 10 after 4 h exposure at the $20 \mathrm{~h}$ time-point. Both $S$. aureus concentrations resulted in significantly increased release of IL-1 $\beta$ from the cultured sputum macrophages $(p<0.05)$ (Figure 7). 


\section{Discussion}

Pulmonary macrophages play an important role in the first line of defense against inhaled particulates and pathogens, and also help orchestrate the immune response and contribute to resolution of inflammation. ${ }^{[8,9]}$ Sputum samples represent secretions from the surfaces of the central airways and are comprised of a mixture of cell populations. ${ }^{[1]}$ The predominant cell type present in sputum samples in healthy individuals are macrophages, with neutrophils occupying relatively lesser percentages, followed by monocytes and lymphocytes. Due to their location, sputum macrophages have the potential to provide valuable information concerning homeostatic as well as pathological mechanisms. However, a method to isolate and then culture these cells for subsequent ex vivo/in vitro experiments has not been optimized. The present study demonstrates successful isolation and culturing of sputum macrophages in healthy volunteers for up to $48 \mathrm{~h}$ post sample collection. We report that $88 \%(35 / 40)$ of the samples acquired were suitable for isolation, and of these $80 \%(32 / 40)$ were successfully progressed through the 2-3 day culturing protocol. Indeed, the isolated macrophages were viable and responsive to in vitro stimulation with LPS and viable $S$. aureus showing significant mRNA TNF $\alpha$ responses and release of IL-1 $\beta$, respectively. This confirmed that the macrophages successfully survived the isolation, adherence and culture conditions applied in this study.

For sputum samples, two processing methods are commonly applied to the raw sample; plug selection or processing of the whole sputum sample. ${ }^{[7]}$ Although these two methods have been reported to provide comparable results with some endpoints,,${ }^{[7,10]}$ plug selection seems to be the commonly preferred method in sputum processing today. However, in the current study we used the whole sputum processing method as it was advantageous in terms of reduced processing times and generating increased recovery of total numbers of immune cells, two factors critical in 
optimizing the isolation and culture conditions of sputum macrophages Advantages of the plug selection method include reduced squamous cell contamination, decreased amounts of salvia, and increased cell viability. ${ }^{[7,10]}$ As important as these factors are for differential cell count and protein analysis, they were not significant effect modifiers with our culture approach. Here, the squamous cell numbers were reduced in the initial seeding step, dead cells were eliminated due to lack of adherence, and saliva was removed during the centrifugation step in the initial processing.

We implemented a $20 \mathrm{~h}$ rest period for the sputum macrophages before the in vitro stimulation exposures were introduced. This was based on preliminary data, and also supported by bronchoalveolar lavage (BAL) data where alveolar macrophages exhibited a marked proinflammatory transcriptional profile that declined after a resting period of 24 to $48 \mathrm{~h} .{ }^{[11]}$ In this study, we observed that gene expression analysis of TNF $\alpha$ decreased dramatically during the prein vitro exposure rest period $(-20 \mathrm{~h}$ to $0 \mathrm{~h})$. Likewise, in alveolar macrophages from BAL, transcriptional responsiveness to inflammatory stimuli (LPS and poly IC) was restored after a resting period $^{[11]}$. This highlights the importance of including a rest or deactivation period prior to culturing sputum macrophages for in vitro stimulation. The enhanced expression of proinflammatory cytokines immediately after culturing could possibly reflect a cellular response to the culturing and attachment on plastic or cellular activation during the isolation procedure ${ }^{[5,11]}$. Alternatively, removal from an anti-inflammatory environment in the airways and from the 'environmental breaks' present there, such as prostaglandin E2 (PGE2) and transforming growth factor $\beta$ (TGF $\beta$ ), could also explain the transient increase in expression of pro-inflammatory cytokines $^{[11-14]}$.

We observed that the number of attached macrophages decreased during the 48 hours in culture, but the mean viability was relatively constant (85\%) for both attached and detached 
macrophages, the latter present in the supernatant. Thus, the detaching of macrophages from the cell culture wells was not due to cell death, but mediated through other mechanisms. The applied isolation method, using cellular attachment to the culture wells, resulted in relatively high cell purity ( $88 \%$ macrophages). Culturing in serum-free medium has been reported to promote adhesion of macrophages. ${ }^{[15]}$ However, the impact of culturing in serum-free medium was not tested in the present study. Macrophage purity was assessed using smaller sized 48 well plates, which limited the possibility of applying vigorous washing that would have otherwise enhanced macrophage purity, although washing could also have resulted in decreased numbers of attached macrophages.

Our initial criteria for progressing isolated macrophages to the culturing procedure, was cell viability $>40 \%$ and total cell number $>10^{6}$. The viability threshold was based on the study from ERS/ATS working group on induced sputum, ${ }^{[7]}$ while the total cell number was based on the necessary number of wells for an in vitro exposure experiment. Of the 35 sputum samples appropriate for adherence isolation, three exhibited a lack of macrophage adherence to the cell culture wells. These samples exhibited viability of $<60 \%$ combined with macrophage proportions of $<60 \%$, reflecting samples dominated by non-macrophage non-adhering cells, e.g. dead cells, squamous cells and neutrophils, most likely leading to an environment sub-optimal for macrophage adherence. Thus, extra attention should be paid to samples with a combination of cell viability $<60 \%$ and macrophage proportions $<60 \%$, as these exhibit a low success rate for attachment after the wash step on Day 1. Overall, our experiences from the series of experiments suggest that the initial criteria of viability $>40 \%$, total cell number $>10^{6}$ were adequate and can be expanded with a criteria of macrophage numbers $>50 \%$. 
Exposure to the toll-like receptor (TLR)-4 agonist LPS $(1 \mu \mathrm{g} / \mathrm{ml})$ resulted in significantly increased expression of TNF $\alpha, \mathrm{IL}-1 \beta$ and IL-6 after 2-5, 8 and 2-8 $\mathrm{h}$ respectively. Moreover, the 4h exposure to viable $S$. aureus at the $20 \mathrm{~h}$ time-point significantly increased the release of IL-1 $\beta$. Together these data demonstrate that these cultured sputum macrophages are responsive to inflammatory stimuli during the entire $24 \mathrm{~h}$ in vitro exposure period. Previous work by our group has shown that cultured sputum macrophages can display different cytokine patterns depending on the stimulating agent. For example LPS, Pam 3 Cys (TLR2 agonist), isoproterenol and the proinflammatory cytokine IL-1 $\beta$, all induced differential responses demonstrating that cultured sputum macrophages have recognition specificity in terms of pro-inflammatory stimuli. ${ }^{[4]}$

Culturing of sputum macrophages constitutes an ex vivo/in vitro human primary macrophage model allowing for in vitro exposure to various inhaled environmental agents like particulate matter, fungi, environmental chemicals etc., commonly studied in other macrophage models. ${ }^{[16,17]}$ However, one must exercise caution in equating this new model with those currently in use. For example, animal and human monocyte-derived macrophage (MDM) models are commonly used to study in vitro exposure to various inhaled environmental agents, ${ }^{[18-21]}$ despite noted differences between MDMs and primary airway macrophages. ${ }^{[10,22-24]}$ Furthermore, our group has shown functional differences between sputum macrophages and BAL macrophages from the same individual while other studies report that BAL macrophages possess different properties than MDMs. ${ }^{[6,7,10]}$ Therefore, cultured sputum macrophages may represent an ex vivo/in vitro model that only applies to immune cells derived from the surfaces of the central airways. Future studies will be needed however, to confirm whether sputum macrophage models are similar or different than other in vitro macrophage models that use MDMs, differentiated cell lines or macrophages acquired from BAL. 
Although the isolation of sputum macrophages by plate adherence resulted in a viable and responsive culture of primary human airway macrophages, the method has some challenges and limitations. First, there are some practical challenges related to the experiment planning. More specifically, the number of wells for in vitro experiments resulting from a sputum induction was unpredictable and varied from 0 to $>100$. This was due to large variations in the yield for viable macrophages $\left(0.5-14.1 \times 10^{6}\right)$ and a success rate for culturing below $100 \%$, since around $20 \%$ of the healthy volunteers provided samples that were not suitable for culturing. Second, the obtained cultures contained some squamous cell contamination (approximately 10\%) and the impact of this contamination on the macrophage responses is not characterized. Finally, there is limited knowledge regarding the impact of the isolation and culturing on the phenotype of the sputum macrophages, which limits the generalizability of the data resulting from these cultures. Tomlinson et al. 2012 encountered similar challenges during culturing of BAL macrophages, and suggested a comparison of cultured macrophages and in situ macrophages in tissue samples to assess the impact of culturing ${ }^{[11]}$.

Induced sputum is a non-invasive method with minimal discomfort for the recruited human volunteers. The described method for isolation and culturing of macrophages from induced sputum samples requires approximately 4 hours work, and was demonstrated to result in airway macrophage cultures of adequate purity and viability. Moreover, successful post-culture activation of the airway macrophages by the TLR agonist LPS and viable $S$. aureus bacteria was demonstrated. Thus, isolation by plate adherence and subsequent culturing of sputum macrophages represents a promising ex vivo/in vitro model in which to examine airway macrophage behavior.

\section{Acknowledgments}


This work was supported by the Norwegian research council under Grant number 228129 and the Working Environmental Fund, Confederation of Norwegian Enterprise. Dr. Håkon Valen Rukke is greatly acknowledged for supervision during planning and conduction of the experiments with the viable bacteria, which were performed at the Nordic institute of Dental Materials (NIOM).

\section{Declaration of interest statement}

The authors declare no conflict of interest. 


\section{References}

1. Alexis NE, Hu SC, Zeman K, Alter T, Bennett WD. Induced sputum derives from the central airways: confirmation using a radiolabeled aerosol bolus delivery technique. American journal of respiratory and critical care medicine. 2001;164(10 Pt 1):1964-1970.

2. Pavord ID, Pizzichini MM, Pizzichini E, Hargreave FE. The use of induced sputum to investigate airway inflammation. Thorax. 1997;52(6):498-501.

3. Horváth I, Donnelly LE, Kiss A, Paredi P, Kharitonov SA, Barnes PJ. Raised levels of exhaled carbon monoxide are associated with an increased expression of heme oxygenase- 1 in airway macrophages in asthma: a new marker of oxidative stress. Thorax. 1998;53(8):668-672.

4. Sikkeland LI, Dahl CP, Ueland T, et al. Increased levels of inflammatory cytokines and endothelin1 in alveolar macrophages from patients with chronic heart failure. PloS one. 2012;7(5):e36815.

5. Sikkeland LI, Kongerud J, Stangeland AM, Haug T, Alexis NE. Macrophage enrichment from induced sputum. Thorax. 2007;62(6):558-559.

6. Alexis N, Soukup J, Ghio A, Becker S. Sputum phagocytes from healthy individuals are functional and activated: a flow cytometric comparison with cells in bronchoalveolar lavage and peripheral blood. Clinical immunology (Orlando, Fla). 2000;97(1):21-32.

7. Hamid $Q$, Kelly MM, Linden $M$, et al. Methods of sputum processing for cell counts, immunocytochemistry and in situ hybridisation. European Respiratory Journal. 2002;20(37 suppl):19s.

8. Grabiec AM, Hussell T. The role of airway macrophages in apoptotic cell clearance following acute and chronic lung inflammation. Seminars in immunopathology. 2016;38(4):409-423.

9. Morales-Nebreda L, Misharin AV, Perlman H, Budinger GR. The heterogeneity of lung macrophages in the susceptibility to disease. European respiratory review : an official journal of the European Respiratory Society. 2015;24(137):505-509.

10. Spanevello A, BeghÉ B, Bianchi A, et al. Comparison of Two Methods of Processing Induced Sputum: Selected versus Entire Sputum. American journal of respiratory and critical care medicine. 1998;157(2):665-668.

11. Tomlinson GS, Booth H, Petit SJ, et al. Adherent human alveolar macrophages exhibit a transient pro-inflammatory profile that confounds responses to innate immune stimulation. PloS one. 2012;7(6):e40348.

12. Gardai SJ, Xiao YQ, Dickinson M, et al. By binding SIRPalpha or calreticulin/CD91, lung collectins act as dual function surveillance molecules to suppress or enhance inflammation. Cell. 2003;115(1):13-23.

13. Roth MD, Golub SH. Human pulmonary macrophages utilize prostaglandins and transforming growth factor beta 1 to suppress lymphocyte activation. Journal of leukocyte biology. 1993;53(4):366-371.

14. Takayama K, Garcia-Cardena G, Sukhova GK, Comander J, Gimbrone MA, Jr., Libby P. Prostaglandin E2 suppresses chemokine production in human macrophages through the EP4 receptor. The Journal of biological chemistry. 2002;277(46):44147-44154.

15. Williams MR, Cauvi DM, Rivera I, Hawisher D, De Maio A. Changes in macrophage function modulated by the lipid environment. Innate immunity. 2016;22(3):141-151.

16. Hansen JF, Bendtzen K, Boas M, et al. Influence of phthalates on cytokine production in monocytes and macrophages: a systematic review of experimental trials. PloS one. 2015;10(3):e0120083. 
17. Lawal AO. Diesel Exhaust Particles and the Induction of Macrophage Activation and Dysfunction. Inflammation. 2018;41(1):356-363.

18. Berntsen HF, Bolling AK, Bjorklund CG, et al. Decreased macrophage phagocytic function due to xenobiotic exposures in vitro, difference in sensitivity between various macrophage models. Food and chemical toxicology : an international journal published for the British Industrial Biological Research Association. 2018;112:86-96.

19. Davies JQ, Gordon S. Isolation and Culture of Human Macrophages. In: Vol 290.2004:105-116.

20. Karlsson H, Lindbom J, Ghafouri B, et al. Wear particles from studded tires and granite pavement induce pro-inflammatory alterations in human monocyte-derived macrophages: a proteomic study. Chemical research in toxicology. 2011;24(1):45-53.

21. Overton NLD, Brakhage AA, Thywissen A, Denning DW, Bowyer P. Mutations in EEA1 are associated with allergic bronchopulmonary aspergillosis and affect phagocytosis of Aspergillus fumigatus by human macrophages. PloS one. 2018;13(3):e0185706.

22. Clift MJ, Endes C, Vanhecke D, et al. A comparative study of different in vitro lung cell culture systems to assess the most beneficial tool for screening the potential adverse effects of carbon nanotubes. Toxicological sciences : an official journal of the Society of Toxicology. 2014;137(1):55-64.

23. Daigneault M, Preston JA, Marriott HM, Whyte MK, Dockrell DH. The identification of markers of macrophage differentiation in PMA-stimulated THP-1 cells and monocyte-derived macrophages. PloS one. 2010;5(1):e8668.

24. Misharin AV, Morales-Nebreda L, Reyfman PA, et al. Monocyte-derived alveolar macrophages drive lung fibrosis and persist in the lung over the life span. The Journal of experimental medicine. 2017;214(8):2387-2404. 
Table 1: Overview of pre-culture sample characteristics of 35 sputum samples that passed the initial criteria for culturing.

The viability originates from the Trypan blue cell count, while the macrophage, neutrophil, eosinophil and lymphocyte percentages were obtained from the differential cell counts performed during sputum processing (pre-culturing).

\begin{tabular}{lcc}
\hline & Mean \pm SD & Median $(\min -\max )$ \\
\hline Sputum weight $(\mathrm{g})$ & $5.7 \pm 2.7$ & $5.3(1.7-12.7)$ \\
Leukocyte viability $(\%)$ & $67.7 \pm 11.8$ & $67.0(44.0-97.0)$ \\
Total viable leukocytes $\left(10^{6}\right)$ & $5.5 \pm 5.3$ & $4.2(0.5-29.0)$ \\
Macrophages (\%) & $68.4 \pm 16.3$ & $72.0(26.0-93.0)$ \\
Neutrophils (\%) & $30.7 \pm 16.8$ & $28.0(6.0-74.0)$ \\
Eosinophils (\%) & $0.1 \pm 0.4$ & $0(0-1.6)$ \\
Lymphocytes (\%) & $0.7 \pm 1.1$ & $0(0-4)$ \\
Total viable macrophages $\left(10^{6}\right)$ & $3.5 \pm 2.9$ & $2.7(0.5-14.1)$ \\
\hline
\end{tabular}




\section{Figure 1:}

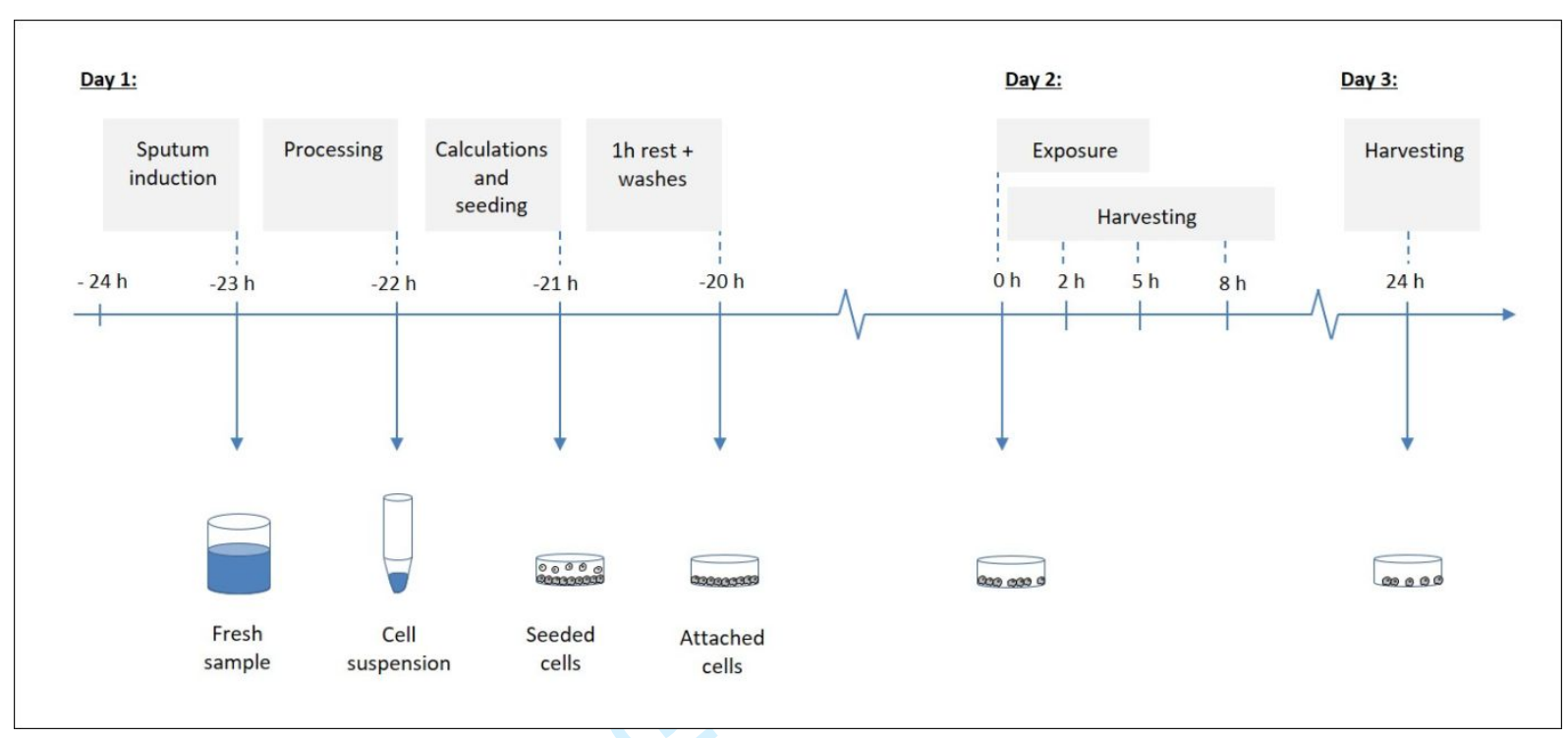


Figure 2:
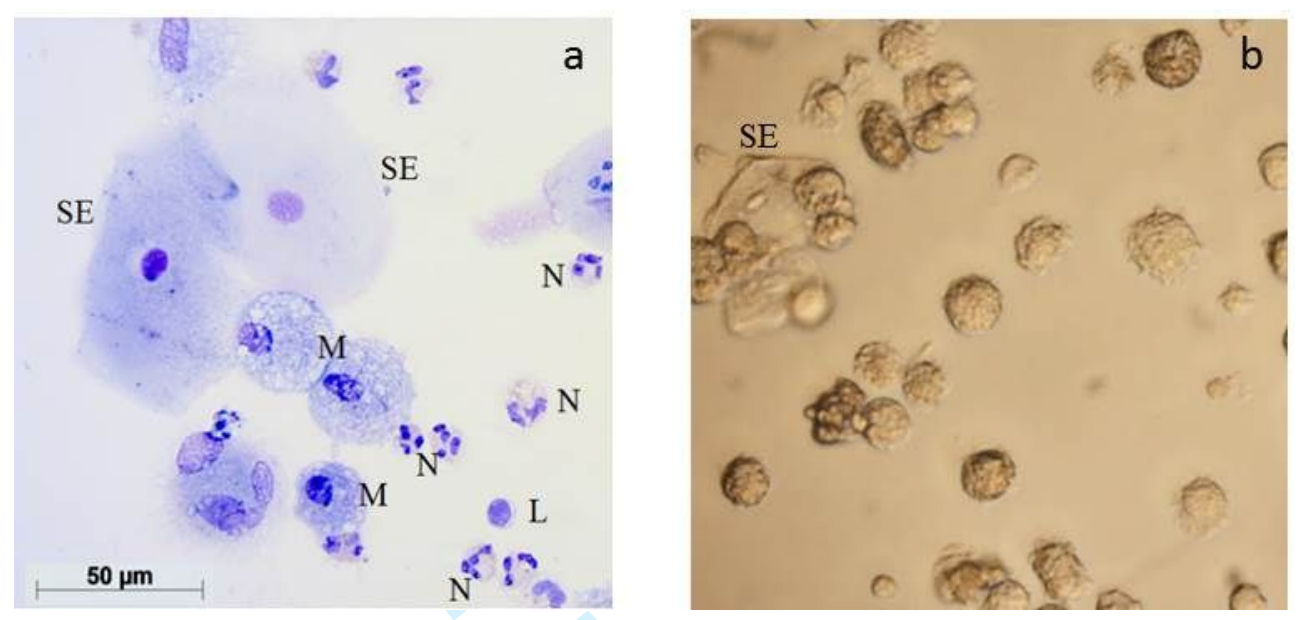
Figure 3:
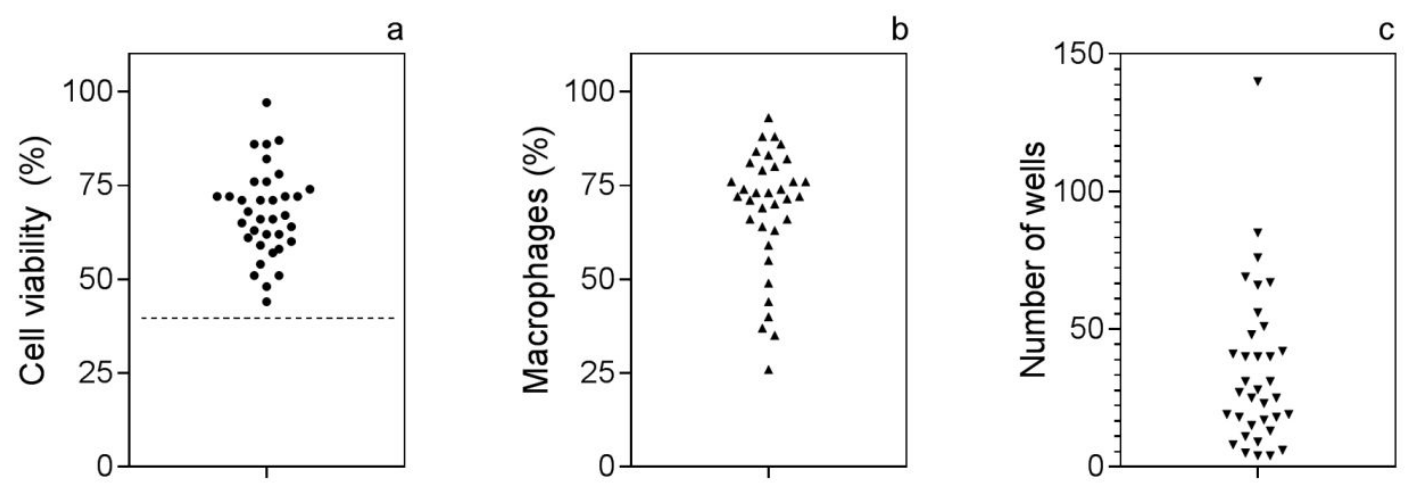
Figure 4:
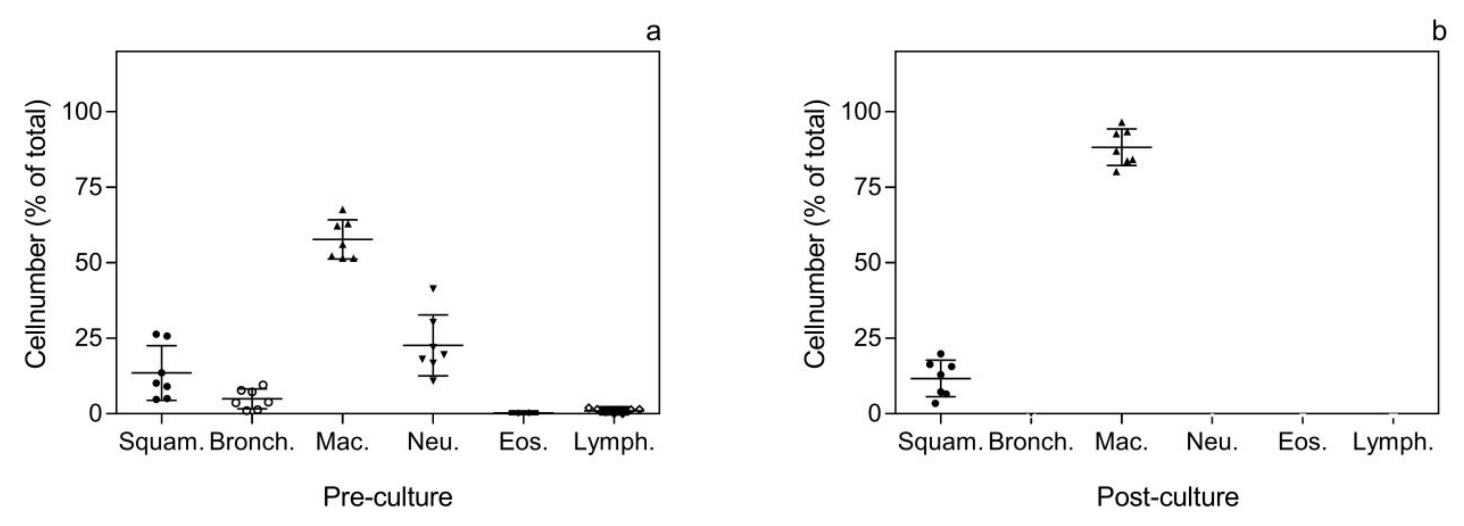
Figure 5:
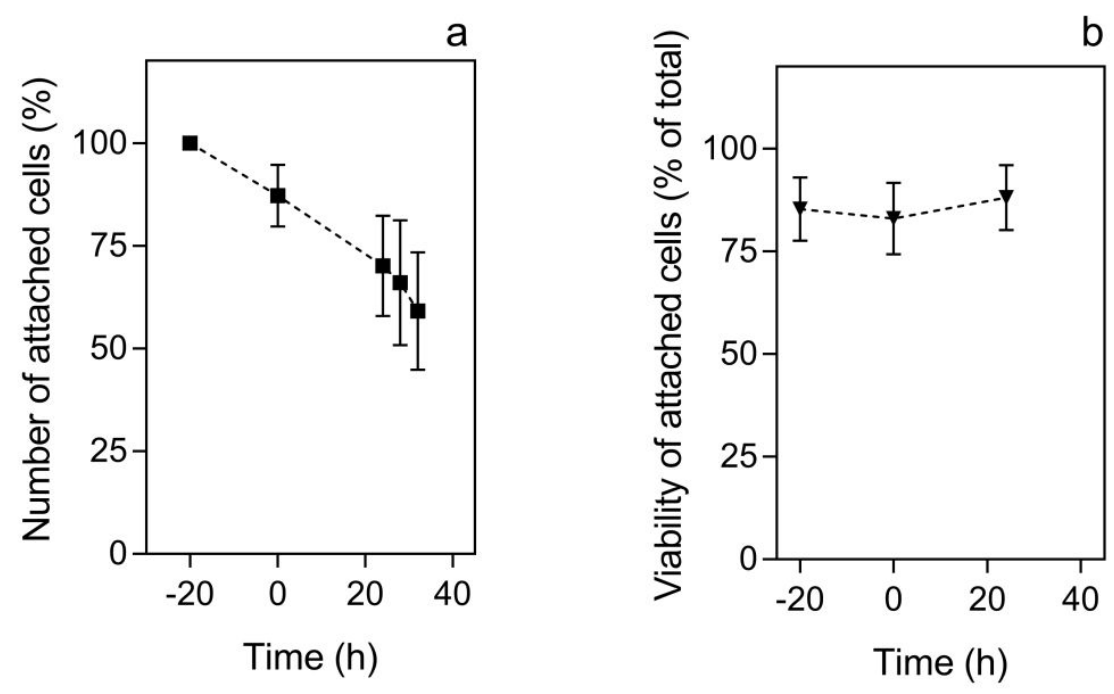
Figure 6:
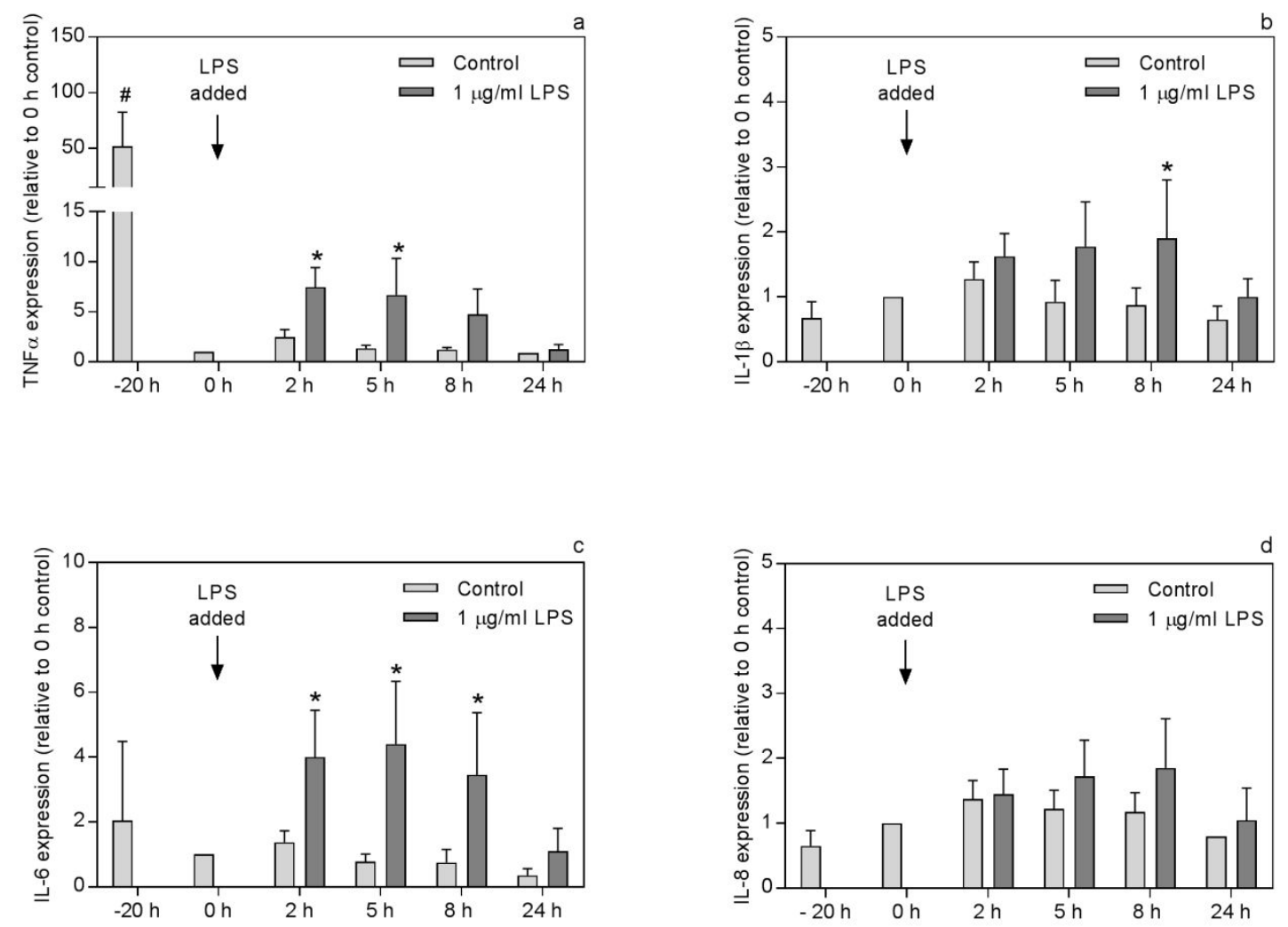
Figure 7:

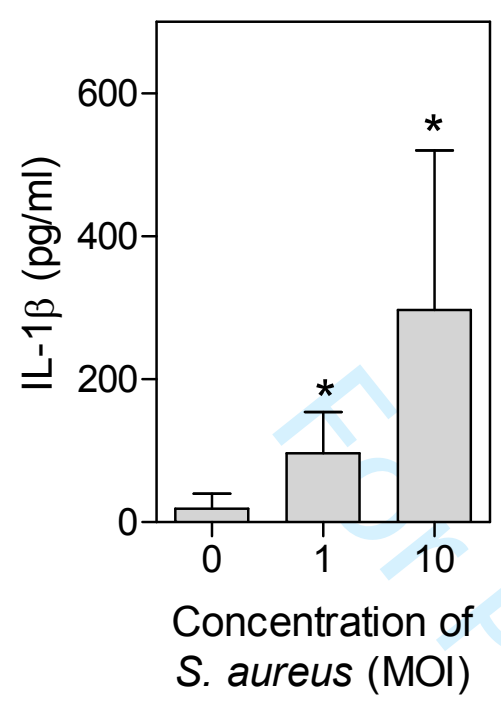




\section{Figure legends}

Figure 1: Schematic illustration of culturing of sputum macrophages. The figure shows the timeline of the processing and culturing of sputum cells, illustrating the approximate $4 \mathrm{~h}$ duration of sputum induction, the sample processing and seeding of cells (including the $1 \mathrm{~h}$ rest allowing for macrophage attachment), the $20 \mathrm{~h}$ over-night rest (Day 1 - Day 2) and the $24 \mathrm{~h}$ exposure period (e.g. LPS (1 ug/ml)) (Day 2 - Day 3). Cells were examined at 2, 5, 8 and $24 \mathrm{~h}$ post LPS exposure.

Figure 2: Light microscopy images of cells before and after culturing. a) A Diff Quik stained cytospin slide was prepared from the cell suspension prior to culturing of the cells. b) Macrophages attached to the surface of the cell culture well after $20 \mathrm{~h}$ of culturing; one squamous epithelial cell is indicated. Abbreviations: $\mathrm{M}=$ macrophage, $\mathrm{N}=$ neutrophil, $\mathrm{SE}=$ squamous epithelial cell, $\mathrm{L}=$ lymphocyte.

Figure 3: Distribution of characteristics for sputum samples for pre-culturing. Dot plots of individual values for a) leukocyte cell viability b) percentage of macrophages and c) the macrophage yield displayed as the number of wells that could be seeded on 48 well plates from the obtained macrophages $(\mathrm{N}=35)$.

Figure 4: Differential cell counts pre- and post-culturing. The graphs show the percentages of squamous (Squam.) and bronchial (Bronch.) epithelial cells, macrophages (Mac.), neutrophils (Neu.), eosinophils (Eos.) and lymphocytes (Lymph.) from the same individuals (N=7) a) preculturing (during processing of the sputum samples) and $\mathrm{b}$ ) at the $0 \mathrm{~h}$ time point (Figure 1 ) for cells detached using Accutase. Absence of symbol reflects absence of cell type in sample. 
Figure 5: Number and viability of attached cells. a) Number and b) viability of attached cells for increasing incubation times, presented as mean $\pm \mathrm{SD}(\mathrm{N}=3-8$ independent experiments). In a) $100 \%$ of attached cells corresponds to $10^{5}$ cells/well in 48 well plates at $-20 \mathrm{~h}$, while mean $\pm \mathrm{SD}$ number of attached cells at $24 \mathrm{~h}$ and $32 \mathrm{~h}$ corresponds to $0.7 \times 10^{5} \pm 0.1 \times 10^{5}$ and $0.6 \mathrm{x}$ $10^{5} \pm 0.1 \times 10^{5}$ cells/well, respectively.

Figure 6: Cytokine gene expression levels. The expression of a) TNF $\alpha, b)$ IL-1 $\beta$, c) IL-6 and d) IL-8 in cultured airway macrophages were determined at $-20,0,2,5,8$ and $24 \mathrm{~h}$ time points. At the $0 \mathrm{~h}$ time point, the cells were stimulated with $1 \mu \mathrm{g} / \mathrm{ml}$ LPS. Data are displayed as fold change from the control value at $0 \mathrm{~h}$ for each experiment (mean $\pm \mathrm{SD}) . * \mathrm{p}<0.05$ stimulated versus unstimulated (Control) cells (2-way ANOVA, with Bonferroni post-tests performed on data from $2--24$ h only, $\mathrm{N}=4$ independent experiments) and \# $\mathrm{p}<0.05-20 \mathrm{~h}$ control vs $0 \mathrm{~h}$ control (One sample t-test; hypothetical value 1 (i.e. $0 \mathrm{~h}$ control value).

Figure 7: Exposure to viable bacteria. Macrophages were exposed to live bacteria (S. aureus) at a MOI of 1 or 10 for $4 \mathrm{~h}$ at the $20 \mathrm{~h}$ time-point. The resulting IL- $1 \beta$ release was measured at the $24 \mathrm{~h}$ time-point. * refers to significant difference from control (repeated measures one-way ANOVA, log-transformed data, Dunnets post-test, $\mathrm{N}=6$ ). 


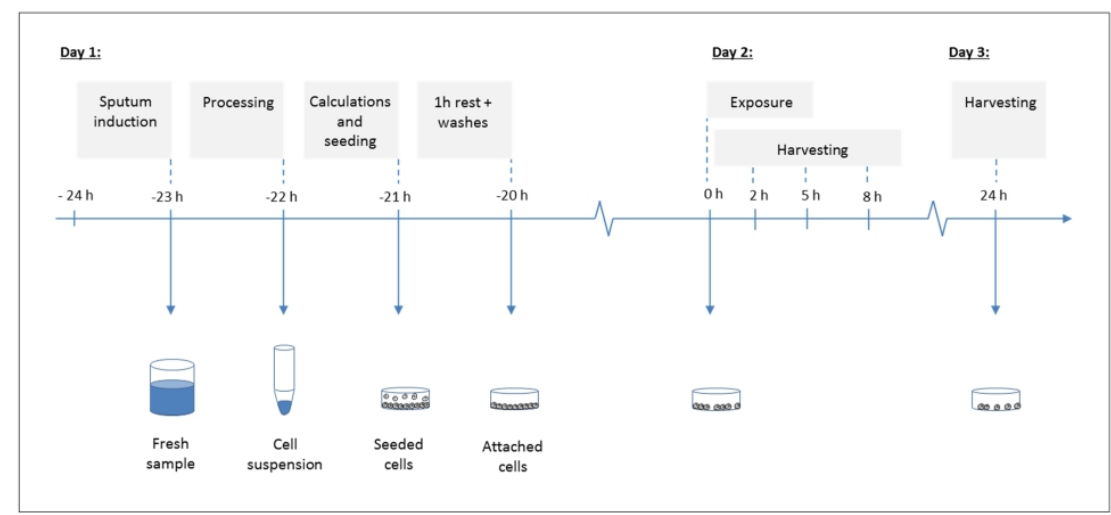

Figure 1: Schematic illustration of culturing of sputum macrophages. The figure shows the timeline of the processing and culturing of sputum cells, illustrating the approximate $4 \mathrm{~h}$ duration of sputum induction, the sample processing and seeding of cells (including the $1 \mathrm{~h}$ rest allowing for macrophage attachment), the 20 h over-night rest (Day 1 - Day 2 ) and the $24 \mathrm{~h}$ exposure period (e.g. LPS $(1 \mu \mathrm{g} / \mathrm{ml})$ ) (Day 2 - Day 3 ). Cells were examined at 2, 5, 8 and $24 \mathrm{~h}$ post LPS exposure.

\section{$297 \times 209 \mathrm{~mm}(300 \times 300$ DPI $)$}


Figure 2: Light microscopy images of cells before and after culturing. a) A Diff Quik stained cytospin slide was prepared from the cell suspension prior to culturing of the cells. b) Macrophages attached to the surface of the cell culture well after $20 \mathrm{~h}$ of culturing; one squamous epithelial cell is indicated. Abbreviations: $\mathrm{M}=$ macrophage, $\mathrm{N}=$ neutrophil, $\mathrm{SE}=$ squamous epithelial cell, $\mathrm{L}=$ lymphocyte.

$297 \times 209 \mathrm{~mm}(300 \times 300$ DPI $)$ 

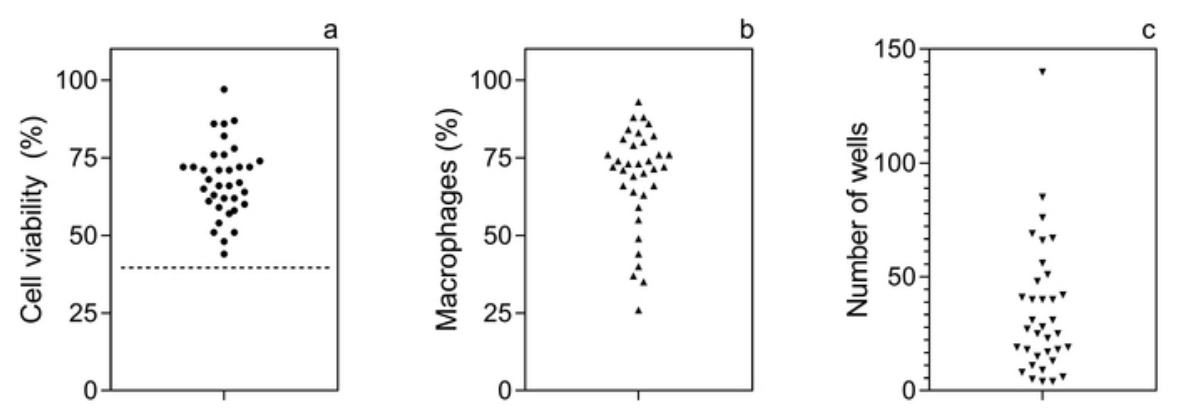

Figure 3

$65 \times 25 \mathrm{~mm}(300 \times 300$ DPI $)$ 

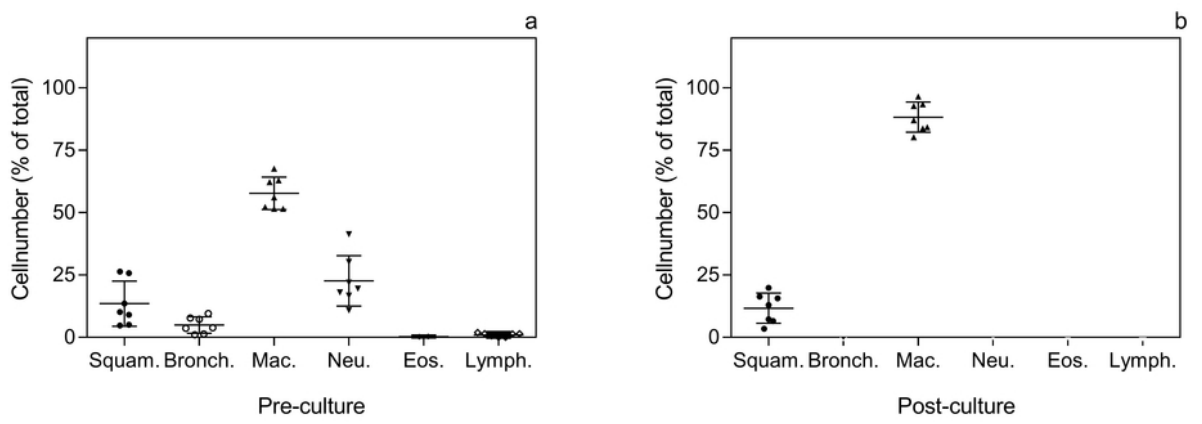

Figure 4: Differential cell counts pre- and post-culturing. The graphs show the percentages of squamous (Squam.) and bronchial (Bronch.) epithelial cells, macrophages (Mac.), neutrophils (Neu.), eosinophils (Eos.) and lymphocytes (Lymph.) from the same individuals $(\mathrm{N}=7)$ a) pre-culturing (during processing of the sputum samples) and b) at the $0 \mathrm{~h}$ time point (Figure 1 ) for cells detached using Accutase. Absence of symbol reflects absence of cell type in sample.

$85 \times 31 \mathrm{~mm}(300 \times 300$ DPI $)$ 


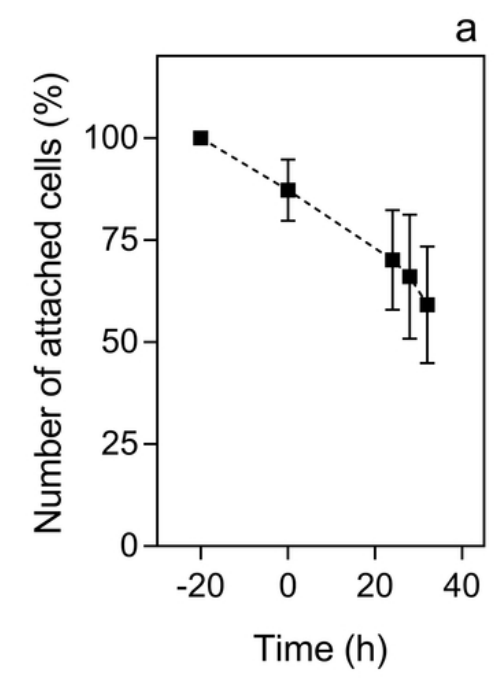

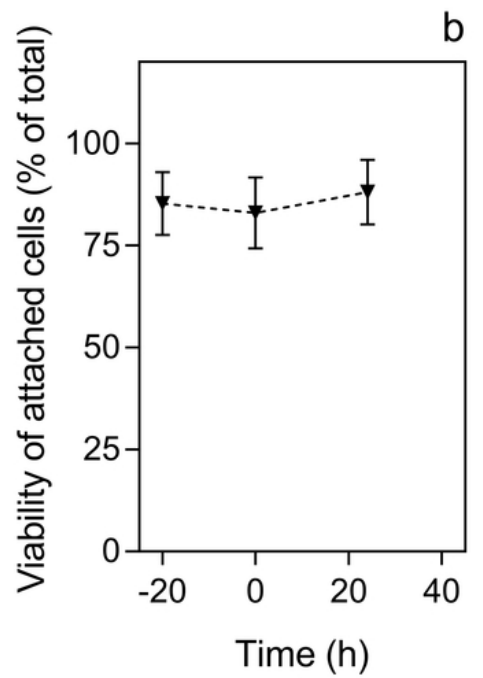

Figure 5: Number and viability of attached cells. a) Number and b) viability of attached cells for increasing incubation times, presented as mean \pm SD ( $N=3-8$ independent experiments). In a) $100 \%$ of attached cells corresponds to $10^{5}$ cells/well in 48 well plates at $-20 \mathrm{~h}$, while mean \pm SD number of attached cells at 24 and $32 \mathrm{~h}$ correspond to $0.7 \times 10^{5} \pm 0.1 \times 10^{5}$ and $0.6 \times 10^{5} \pm 0.1 \times 10^{5}$ cells/well, respectively. 

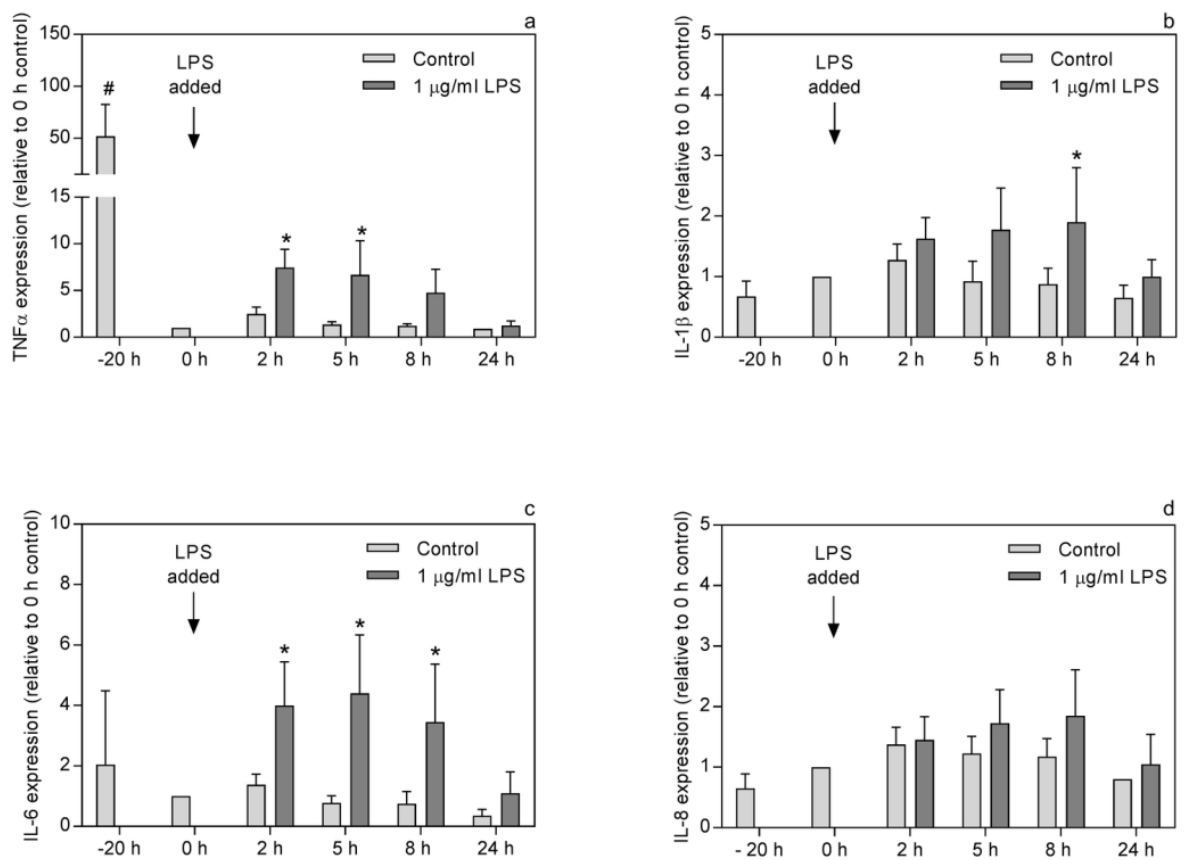

Figure 6: Cytokine gene expression levels. The expression of a) TNFa, b) IL-1 $\beta, c)$ IL-6 and d) IL-8 in cultured airway macrophages were determined at $-20,0,2,5,8$ and $24 \mathrm{~h}$ time points. At the $0 \mathrm{~h}$ time point, the cells were stimulated with $1 \mu \mathrm{g} / \mathrm{ml}$ LPS. Data are displayed as fold change from the control value at $0 \mathrm{~h}$ for each experiment (mean $\pm \mathrm{SD}$ ). ${ }^{*} \mathrm{p}<0.05$ stimulated versus unstimulated (Control) cells (2-way ANOVA, with Bonferroni post-tests performed on data from $2--24 \mathrm{~h}$ only, $\mathrm{N}=4$ independent experiments) and \# $\mathrm{p}<0.05-20 \mathrm{~h}$ control vs $0 \mathrm{~h}$ control (One sample t-test; hypothetical value 1 (i.e. $0 \mathrm{~h}$ control value).

$139 \times 100 \mathrm{~mm}(300 \times 300$ DPI $)$ 


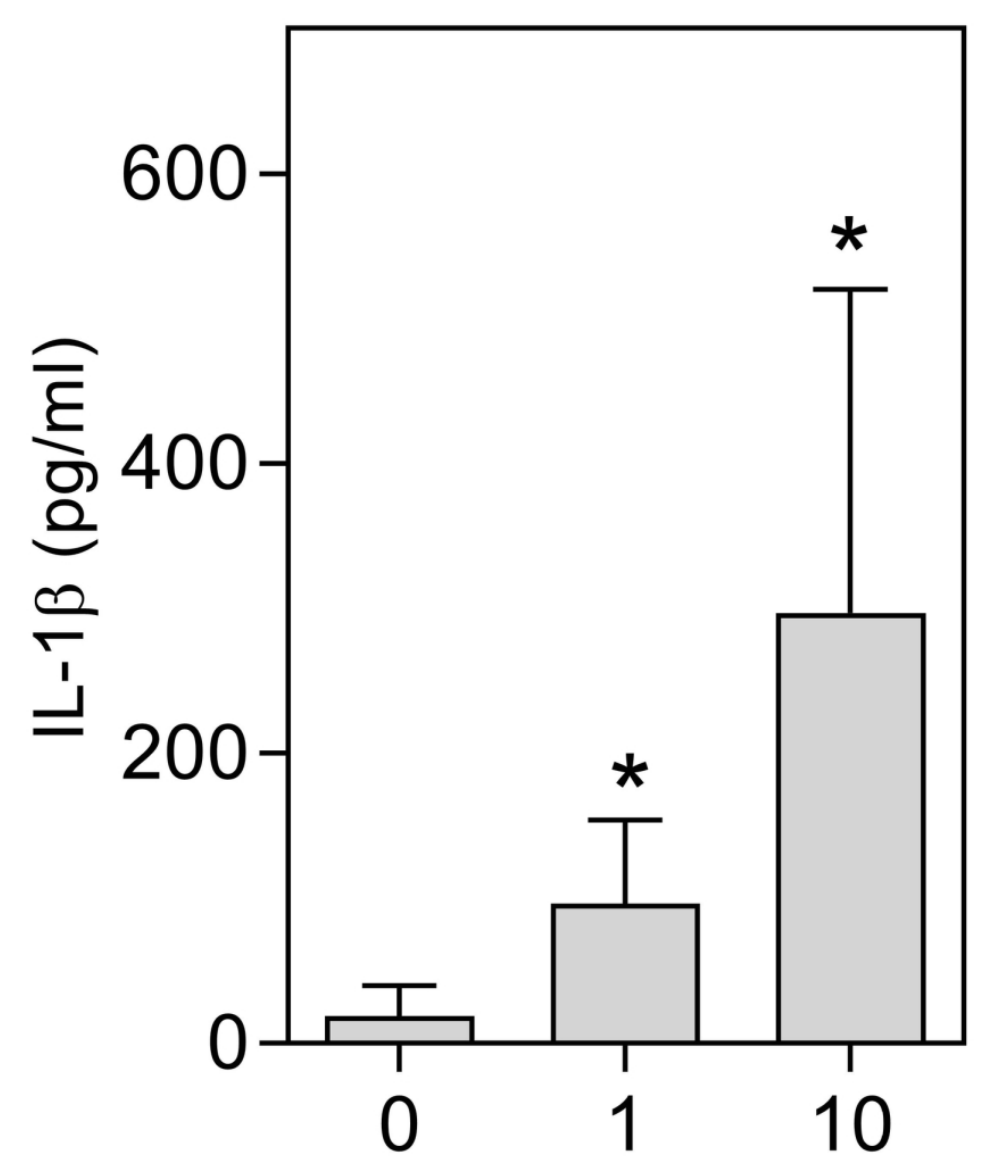

\section{Concentration of S. aureus (MOI)}

Figure 7: Exposure to viable bacteria. Macrophages were exposed to live bacteria (S. aureus) at a MOI of 1 or 10 for $4 \mathrm{~h}$ at the $20 \mathrm{~h}$ time-point. The resulting IL-1 $\beta$ release was measured at the $24 \mathrm{~h}$ time-point. * refers to significant difference from control (repeated measures one-way ANOVA, log-transformed data, Dunnets post-test, $\mathrm{N}=6$ ).

$156 \times 193 \mathrm{~mm}(300 \times 300$ DPI $)$ 